\title{
A Comparative Study of Dispersion Techniques for Nanocomposite Made with Nanoclays and an Unsaturated Polyester Resin
}

\author{
Farida Bensadoun, Nadir Kchit, Catherine Billotte, François Trochu, and Edu Ruiz \\ Chair on Composites of High Performance (CCHP), Research Centre on Plastics and Composites (CREPEC), \\ Department of Mechanical Engineering, École Polytechnique de Montréal, P.O. Box 6079, Station Centre-Ville, \\ Montreal, QC, Canada H3C $3 A 7$ \\ Correspondence should be addressed to Edu Ruiz, edu.ruiz@polymtl.ca
}

Received 12 April 2011; Revised 19 July 2011; Accepted 23 August 2011

Academic Editor: Gaurav Mago

Copyright ( 2011 Farida Bensadoun et al. This is an open access article distributed under the Creative Commons Attribution License, which permits unrestricted use, distribution, and reproduction in any medium, provided the original work is properly cited.

\begin{abstract}
Over the last few years, polymer/clay nanocomposites have been an area of intensive research due to their capacity to improve the properties of the polymer resin. These nanocharged polymers exhibit a complex rheological behavior due to their dispersed structure in the matrix. Thus, to gain fundamental understanding of nanocomposite dispersion, characterization of their internal structure and their rheological behavior is crucial. Such understanding is also key to determine the manufacturing conditions to produce these nanomaterials by liquid composite molding (LCM) process. This paper investigates the mix of nanoclays particles in an unsaturated polyester resin using three different dispersion techniques: manual mixing, sonication, and high shear mixing (HSM). This paper shows that the mixing method has a significant effect on the sample morphology. Rheology, scanning electron microscopy (SEM), and differential scanning calorimetry (DSC) characterization techniques were used to analyze the blends morphology and evaluate the nanoclays stacks/polymer matrix interaction. Several phenomena, such as shear thinning and premature polymer gelification, were notably observed.
\end{abstract}

\section{Introduction}

Recent advances in the composite materials field are related to the addition of nanoparticles such as carbon nanotubes or nanoclays to improve thermal, mechanical, or electrical properties. Nanoparticle additives, like nanoclays, are widely used in various industries such as cable coatings, adhesives, inks, pharmaceuticals and automotives $[1,2]$. One of the most common nanoclay forms is MMT layered silicate with a particle thickness of $1 \mathrm{~nm}$ and 70 to $100 \mathrm{~nm}$ crosswise silica platelets [3]. The choice of montmorillonite nanoparticles in previous researches is mainly due to the fact that they are commonly available in nature and inexpensive. A minimal content of such additives between 1 to $6 \%$ wt can improve the properties of the polymer matrix by increasing flexural modulus by up to $31 \%$ and lowering the coefficient of linear thermal expansion by $66 \%[1,4,5]$. However, the incorporation of nanoparticles into the liquid matrix is still a challenge, because it requires proper dispersion and exfoliation. Nanoclays are widely used in thermoplastic matrices, but only few studies report to their addition in polyester thermoset resins. This explains the lack of results on the thermal and mechanical properties and especially on the rheology of the mix.

Rheology is a widely used evaluation method for detecting the presence of interconnected structures. This technique seems to be relevant for the study of the dispersion state which defines the nanostructure of the mixture between the conventional, the intercalated, or exfoliated nanocomposite as illustrated in Figure 1. However, in practice, the final mixture would probably be a combination of these three morphologies, where the best-case scenario is the fully exfoliated structure $[1,6]$. Due to the high aspect ratio of the platelets, a small percentage of nanoclay particles properly dispersed in the matrix can generate a very large surface 


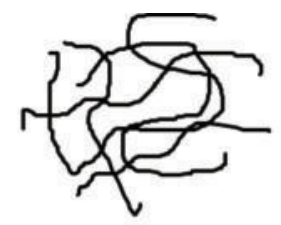

Polymer

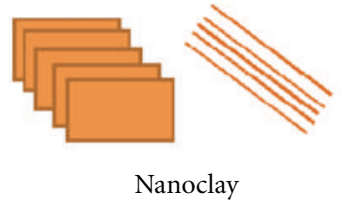

platelets 1

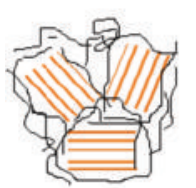

Conventional nanocomposite

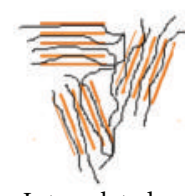

Intercalated

nanocomposite

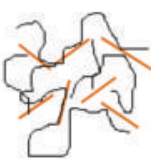

Exfoliated nanocomposite
FIGURE 1: States of dispersion of nanoclay platelets.

area for polymer/filler interactions $[1,6]$. Many factors can influence the dispersion and exfoliation of the nanoparticles in the polymer. The final properties of the nanostructure will mainly depend on the choice of the mixing technique and the resulted degree of exfoliation of the nanoclay platelets $[7,8]$. Techniques such as in situ polymerization, solution mixing, or sonication are widely used to disperse nanoparticles in a liquid. The latter technique in particular seems to be relatively effective to obtain an exfoliated structure $[1,9,10]$. The changes of morphology of the mix are associated to the dispersion of the nanoparticles in the liquid matrix. When using a Newtonian polymer, the morphology change is detectable with rheology analyzes by the apparition of a shear-thinning behaviour $[1,7,11,12]$. This non-Newtonian behaviour can be attributed to various factors such as the change in the nanoparticles volume fraction, shape, and size or size distribution $[6,12]$. This decrease of viscosity is due to the reorientation of the layered silicate (MMT) in the direction of flow in response to the external applied shear $[8,13,14]$. The degree of the shear-thinning can then be used as an indicator of the exfoliation state of the nanoclays inside the polymer matrix; a steeper slope can be associated to an exfoliated mixture $[7,8]$. When the shear stress is released after testing, a restructuration to the original disorganized structure of the nanoclay is initiated. The viscosity of the blend gradually go back to its original steady-state value [13].

The presence of layered silicates in nonaqueous polymers changes the viscoelastic behavior of the unfilled matrix from liquid-like $\left(\mathrm{G}^{\prime} \alpha \omega^{2}\right)$ to solid-like $\left(\mathrm{G}^{\prime} \alpha \omega^{0}\right)$ because of the formation of a three-dimensional percolating network of exfoliated or intercalated stacks [15]. This gel-like behavior is a direct consequence of the highly anisotropic nature of the nanoclays which prevents their free rotation and the dissipation of stress [16]. This superstructure formation will directly affect the polymerization reaction $[14,17,18]$. The presence of this gel-like structure limits the cross-linking altering the curing reaction because of the reduction of the molecular mobility and thus free volume [19]. This limitation is not attributed to the resin nature itself which generally follows the rule of mixtures, but to the presence of nanoclays leading to a more complex chemical behavior [20]. According to Gholizadeh et al. [21], the addition of nanoclay decreases the free volume. On the other hand, Yu et al. [22] observed an increase in free volume after the addition of bentonite clay attributed to the cyanate ester polymer/nanoparticles interaction. The effect of the nanoplatelets on the free volume depends on the clay/polymer interactions, and this type of characterization seems to give contradicting results. These interactions can be affected by the interfacial region, the interstitial cavities of agglomerates, the chain segments mobility of the polymer, or the crosslinking density [23]. The composition of the polymer matrix and the nanoclay surface treatment will also influence the curing reaction $[20,24]$.

From the manufacturing point of view, the gel time is a critical parameter for proper composites molding [25, 26]. It was observed in the past that the level of exfoliation of nanoclay platelets has an important impact on resin cure causing premature cross-linking [17]. Goertzen et al. [27] did a rheokinetic study on fumed silicate nanocharged cyanate ester resin at various volume fraction up to $3.4 \%$. They have observed a reduction in gel time by $9 \%$ during isothermal cure at $130^{\circ} \mathrm{C}$ because of the nanoparticles. In similar way, the addition of nanoclay to an epoxy/diamine resin was found to enhance the curing reaction [28]. Generally speaking, the organoclays tend to facilitate the homopolymerisation reaction because of the catalytic action of the octadecylammonium ions of the clays [24, 28, 29].

Other techniques, such as electron microscopy and XRD, are also widely used to characterize the dispersion state of the nanoparticles in the polymer matrix. Due to its high resolution, TEM is suitable only at nanoscale which is not necessarily representative of the entire composite sample at the macroscale. Moreover, sample preparation for TEM analysis is quite complex and time consuming, and results are not guaranteed regarding the cost of such characterization. On the other hand, SEM allows observations of the nanocomposites internal structure at larger scales than TEM. The micro-scale could reveal the size and distribution of agglomerates in a more representative sample [30]. Combined to rheology characterization, SEM microscopy is a good indicator of the dispersion of nanoparticles in the resin and may also confirm the level of exfoliation.

This present study focuses on the mixing techniques and the understanding of the dispersion of nanoclays in unsaturated polyester resin. The main challenge is to achieve exfoliation of large stacks of clay nano-platelets into single layers keeping in mind the manufacturing process limitations. A previous study [31] already identifies the main process parameters to consider for proper injection of a nanoclay reinforced resin and impregnation of natural fibers by LCM. This work has also shown improved mechanical and flammability properties of nanoclay reinforced UP. Three dispersion methods were investigated on this study: manual mixing, sonication, and high shear mixing will be investigated. The dispersion state of nanoparticles in the 
TABle 1: Properties of the nanoclay platelets used in this work.

\begin{tabular}{lccl}
\hline Type & D-spacing & Density & Surface treatment \\
\hline $\begin{array}{l}\text { Cloisite } \\
\text { 30B }\end{array}$ & $18.5 \AA$ & $1.98 \mathrm{~g} / \mathrm{mL}$ & $\begin{array}{l}\text { Alkyl quaternary } \\
\text { ammonium bentonite }\end{array}$ \\
\hline
\end{tabular}

matrix will be evaluated using both rheology and SEM analyses. The catalytic effect of the nanoclays will also be investigated by gel time measurements and cure kinetics study using rheology and M-DSC techniques. The main objective of this research is to identify the most efficient dispersion technique and its impact on rheological and cure kinetics on nanocharged UP matrix keeping in consideration future manufacturing possibilities.

\section{Experimental}

2.1. Material. In this work, an unsaturated polyester petroleum-based resin (UP) R937-DPE24 from AOC was used, which has an average viscosity of $0.1804 \mathrm{~Pa} . \mathrm{s}$ at $23^{\circ} \mathrm{C}$. The resin was prepromoted with cobalt ethylhexanoate and initiated using $1.5 \mathrm{phr}$ of methyl ethyl ketone peroxide (MEKP 925) from Norox. The resin was reinforced using 3\% wt of Cloisite 30B nanoclay from Southern Clay Products. These nanoparticles are organically modified layered magnesium aluminum silicates and their properties are summarized in Table 1.

2.2. Nanoclay Dispersion. A good dispersion is a key challenge to achieve the best possible combination of matrixnanoparticles. For that reason, a new dispersion technique using high shear mixer was investigated in this work and compared to sonication and manual mixing. The choice of the $3 \%$ wt Cloisite 30B was notably based on previous researches $[31,32]$ showing that these type of nanoparticles are easier to disperse due to their chemistry providing general improvement on the matrix properties. Furthermore this type of nanoclay was investigated in an earlier study focusing on composites manufacturing [31], and the mass fraction of $3 \% \mathrm{wt}$ was considered adequate for RTM processing.

The sonication and manual preparations are detailed in a previous study [31]. In these techniques, the nanoclays were incorporated and predispersed in styrene first. The resin was then added to the mix and the styrene in excess was evaporated using high-speed mechanical stirring. The amount of each component was weight controlled. Since the HSM is performed in a sealed chamber, the nanoclays were directly incorporated into the resin. The gap in the geometry interaction chamber has been fixed between 50 and 100 microns, and the resin was circulated inside the chamber at high pressure. The size of particles agglomerates was significantly reduced with this mixing technique resulting in a welldispersed and homogeneous blend. Figure 2 summarizes the blend preparation procedures with the different approaches. The letter A refers to sonication technique whereas the letters $\mathrm{B}$ to high shear mixing. Pure and nanocharged resins were mixed by three methods in order to take into account the possible effect of the mixing technique on the resin itself. The temperature and pressure were maintained at $23^{\circ} \mathrm{C}$ and $1 \mathrm{~atm}$ for (A0) and (A1) blends to limit the possible formation of microgels or styrene evaporation.

2.3. Rheology and Electron Microscopy. Rheology experiments were conducted using a combined motor and transducer (CMT) rheometer MCR501 from Anton-Paar. Both steady shear and small amplitude oscillatory shear (SAOS) measurements were carried out using two types of geometries: parallel plates of $25 \mathrm{~cm}$ diameter with a constant gap of $1 \mathrm{~mm}$ for high-viscosity blends and concentric cylinders for low-viscosity blends. All experiments were conducted at $23^{\circ} \mathrm{C}$ and before measurement the sample was left in the geometry for stabilization for 20 minutes. Plastic paraffin films (parafilm) were placed above the mixtures to limit styrene evaporation during the stabilisation stage. This film limits the air contact of the liquid resin and styrene evaporation can be neglected. The steady shear measurements were performed using a shear rate varying from 0.1 to $1000 \mathrm{~s}^{-1}$.

For steady shear viscosity, the non-Newtonian viscosity $\eta$ is defined as follows $[19,33]$ :

$$
\eta(\dot{\gamma})=\frac{-\tau_{21}}{\dot{\gamma}}
$$

where $\tau_{21}$ is the shear stress, and $\dot{\gamma}$ the shear rate applied. The SAOS experiments were carried out under strain amplitudes of $1 \%$, inside the linear viscoelasticity (LVE) domain. Frequency sweep test measurements were performed at frequencies varying from 0.1 to $100 \mathrm{~Hz}$. A strain wave was imposed to the sample and the SAOS shear stress response $\tau_{21}(t)$ defined as follows $[19,33]$ :

$$
-\tau_{21}(t)=\left(\tau_{0} \cos (\delta)\right) \sin (\varpi t)+\left(\tau_{0} \sin (\delta)\right) \cos (\varpi t),
$$

where $\tau_{0}$ is the stress amplitude, $\emptyset$ the angular frequency, and $\delta$ the phase difference between the strain wave and the stress response. For elastic solids, the shear stress is directly proportional to the strain imposed as defined by Hooke's law:

$$
\tau_{21}=-G \cdot \gamma_{21}=-G \cdot \gamma_{0},
$$

where $\gamma_{0}=\dot{\gamma}_{0} / \omega$ is the strain amplitude and $G$ the elastic modulus. Equations (2) and (3) can be combined to obtain the SAOS material function:

$$
-\frac{\tau_{21}}{\gamma_{0}}=G^{\prime} \sin (\omega \cdot t)+G^{\prime \prime} \cos (\omega \cdot t), \quad \tan (\delta)=\frac{G^{\prime \prime}}{G^{\prime}},
$$

where $G^{\prime}$ is the storage modulus and $G^{\prime \prime}$ the loss modulus, related, respectively, to the energy stored (elastic contribution) and dissipated (viscous contribution). The ratio between modulus is defined as the damping factor $\tan \delta$. The complex viscosity $\eta *(\omega)$ is finally defined as

$$
\eta *(\omega)=\frac{-\tau_{21}(t)}{\dot{\gamma}_{21}(t)},
$$

where $\dot{\gamma}_{21}(t)$ is the SAOS strain rate. 


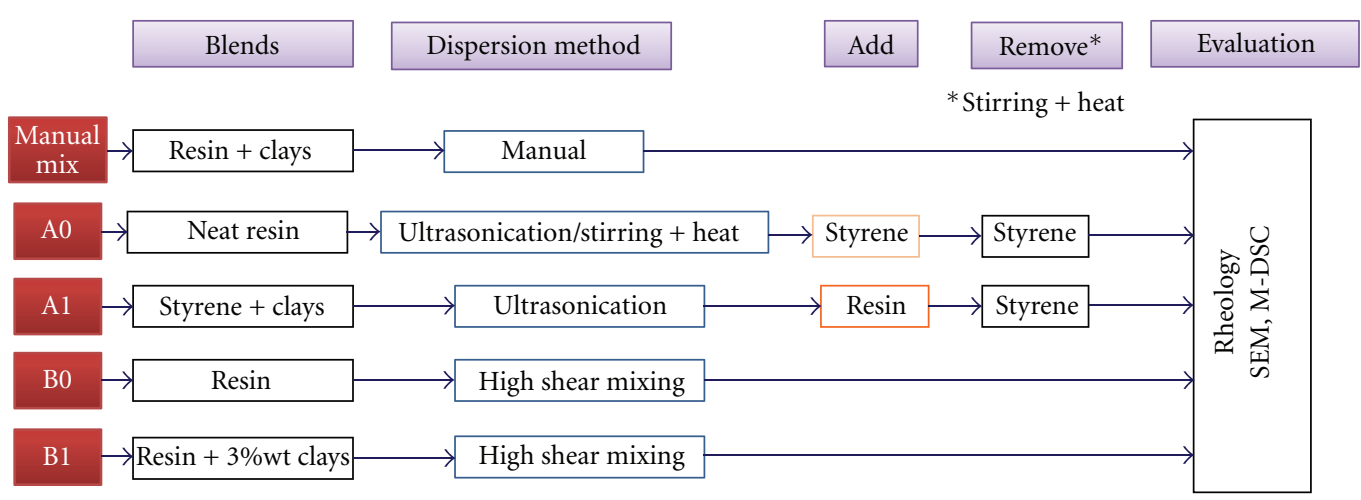

FIGURE 2: Mixing techniques used for nanoclay dispersion in the resin matrix: manual mixing, sonication (a), and high shear mixing (b).

In order to quality the size of the agglomerates and thus, evaluate the quality of the nanoreinforced blends, scanning electron microscopy (SEM) technique is used. A field emission gun scanning electron microscope (FEG-SEM4700) from Hitachi is used at an operation voltage of $2 \mathrm{kV}$. FEG-SEM was used to investigate the distribution of clay in the Epoxy matrix. The smooth and flat surface of specimens were prepared using Ultracut FC microtome (Leica) with a diamond knife and then coated with platinum. This device cuts thin slices of nanocomposite to the desired thickness and the observed area is around $100 \mu \mathrm{m}$.

2.4. Calorimetry. The addition of nanoclay particles in the UP resin can cause premature cross-linking of the matrix which could be the source of composite part failure and restrict the manufacturing capabilities. Consequently, it is important to understand the effects of nanoclays on the resin cure kinetic. In order to see the possible catalytic effect of nanoparticles, calorimetry experiments were performed on blends $\mathrm{A}$ and $\mathrm{B}$ and on the resin alone. First, the samples were isothermally maintained at $70^{\circ} \mathrm{C}$ for different periods of time up to 24 hours in order to study the effect of the storage conditions on the nanocharged mixtures. Afterwards, the MEKP catalyst was added to the blend and samples were cured on the DSC at a dynamic ramp of $10^{\circ} \mathrm{C} / \mathrm{min}$ from room temperature to $250^{\circ} \mathrm{C}$. The instrument used on this study is a modulated differential scanning calorimeter (MDSC) Q1000 from TA Instrument. This instrument has the great advantage of being able to separate the heat flow related to the cure kinetic from the changes in thermodynamic heat capacity. The instantaneous heat generated during the polymerization reaction can be expressed as follows [26, 34]:

$$
\frac{d H}{d t}=\Delta H_{R} \frac{d \alpha}{d t}
$$

where $\Delta H_{R}$ is the total heat of reaction measured by M-DSC and $d \alpha / d t$ the reaction rate. If the diffusion of chemical species is neglected, the reaction rate is assumed to be a unique function of the degree of conversion $\alpha$ and temperature $T$ and this expression takes the form of

$$
\frac{d \alpha}{d t}=f(T, \alpha), \quad \alpha=\int_{0}^{t} \frac{d \alpha}{d t} \cdot d t
$$

and the total heat of reaction corresponds to the area under the nonreversing heat flux curve measured by M-DSC $[26,34]$.

\section{Results and Analyses}

3.1. Rheology Analyses. In this work, the quality of the dispersion of nanoclays in the liquid resin was evaluated from rheology tests knowing that a high initial viscosity and strong shear thinning behavior are often associated to a high level of exfoliation of the nanoclay platelets $[1,6]$. This rheological behavior illustrates the ability of the nanoclays to "interact" with the polymer matrix and is intimately related to the clay type, its surface treatment, and affinity with the polymeric matrix $[6,32]$.

Figure 3 illustrates the viscosity change with shear rate for eight samples dispersed by three different mixing techniques. As shown, the resin viscosity increases after the addition of the nanoparticles with the three mixing techniques studied in this work. The initial viscosity can rise over 3 decades. The mixing techniques does not influence the pure resin viscosity as illustrated by the $\mathrm{A} 0$ and $\mathrm{B} 0$ curves showing the same Newtonian behavior with a viscosity around 0.20 Pa.s, close to the manufacturer data of 0.1804 Pa.s. For the manually mixed blend, the size of particles is probably still quite large due to high probability of aggregates. The sonication mix (A1) results in a slight non-Newtonian shear thinning behavior with an increase of the initial viscosity to 0.80 Pa.s. This can be attributed to a better dispersion and possible intercalation of the nanoclay platelets. On the other hand, the high shear mixing (B1) blends show a strong shear thinning behavior with an initial viscosity varying from 70 to 250 Pa.s. The initial viscosity increases with the number of passes in the high shear chamber. However, at higher shear rates $\left(20 \mathrm{~s}^{-1}\right.$ and over), the viscosity of the nanoreinforced resin is below 10 Pa.s. This value has been previously estimated as the processability limit to manufacture composite parts by RTM [31]. In the case of the high shear mixing blends, the number of passes will have an important influence on the initial viscosity of the nanocharged resin. After two passes, the nanoclays platelets seem to reach their maximum possible exfoliated state, the interactions between the platelets are 

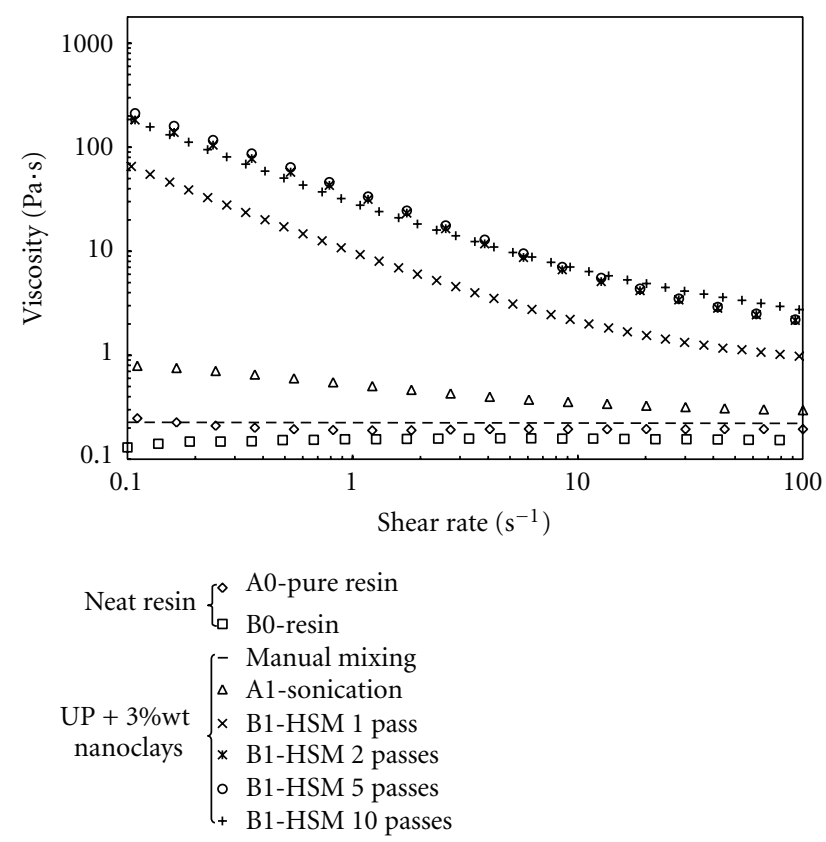

FIGURE 3: Shear viscosity of pure resin and nanocharged resin with $3 \%$ wt $\mathrm{C} 30 \mathrm{~B}$ using different mixing methods.

maximized, and there is no more space for further stacks exfoliation. From these results, it can be concluded that the (B1) high shear mixing technique is more suitable to obtain a potentially exfoliated structure.

The non-Newtonian behavior of the shear viscosity curves of blends A and B can be attributed to the creation of hydrogen bonds to the oxygen groups on the surface of the $\mathrm{C} 30 \mathrm{~B}$ clay platelets and the polar groups of the polymer backbone [27]. A steeper decrease of the viscosity slope, observed for the HSM blends, is a sign of an enhanced shearthinning behavior. According these results, the dispersion state is probably exfoliated. This behavior may also be due to a loss in local entropy enhancing the movement of the polymer chains in flow direction [8].

Figures 4(a) and 4(b) illustrate the variations in storage moduli $G^{\prime}$ and damping factor $\tan \delta$ with frequency for the three mixing techniques evaluated on this work. The mixing method has a major impact on the storage modulus, as shown in Figure 4(a) by the differences in $G^{\prime}$ between the manual, sonication (A1), and high shear mixing (B1). The storage modulus of the manual and (A1) blends show an almost second-order dependency with frequency $\left(G^{\prime} \alpha \omega^{2}\right)$, with slopes of 1.541 and 1.131, respectively. This is a typical behaviour of liquid-like blends and can be attributed to a probably intercalated morphology of the nanoclays. As for the high shear mixed blends (B1), $G^{\prime}$ is quasi-independent of the frequency indicating an almost gel-like structure $\left(G^{\prime} \alpha \omega^{0}\right)$ with slopes varying from 0.368 to 0.263 for 1 to 5 passes [3]. This behaviour induces one to believe the formation of a 3D polymer/nanoclays network [6]. Furthermore, the increase of $G^{\prime}$ with the number of passes in the HSM is a direct consequence of the enhancement of the dispersion of nanoclays which could lead to an exfoliated state. It has to be noted that no accurate values of $G^{\prime}$ were detected for frequencies below $0.1 \mathrm{rad} / \mathrm{s}$ due to the precision of the rheometer. In Figure 4(b), small variations of $\tan \delta$ for the HSM mixtures at low frequency are observed, which confirms the gel-like structure of these blends. However, these are considered to be weak gels, because the ratio between the dissipative $\left(G^{\prime \prime}\right)$ and elastic energy $\left(G^{\prime}\right)$ is low, between 0.1 and 0.7 . So the viscous nature still dominates the elastic behaviour in opposite to a strong gel $(\tan \delta$ below $10^{-2}$ ) [35]. At almost $\omega=10 \mathrm{rad} / \mathrm{s}$, the $\tan \delta$ value reaches a maximum for the (A1) and manual blends (peak of the bell shape). This marks a transition to a more dissipative behaviour, meaning a transition from a gel-like state to a liquid-like state. This behaviour can be related to the alignment of the platelets in the flow direction. For the (B1) blends, a slight increase of $\tan \delta$ and $G^{\prime}$ at $10 \mathrm{rad} / \mathrm{s}$ can be observed, indicating the beginning of a morphological change. At higher frequencies ( $\omega>62.8 \mathrm{rad} / \mathrm{s}), G^{\prime}$ seems to tend to the same value for all systems. It was finally found that at high frequencies, the $G^{\prime}$ response is dominated by the matrix since the values of all mixtures trend to $1000 \mathrm{~Pa}$ at $628 \mathrm{rad} / \mathrm{s}$ [3].

To validate the rheology results showing the differences in dispersion of the nano-platelets, visual observation was performed using SEM and micrographs of the blends as illustrated in Figure 5. Note that the unidirectional etchings on the micrographs are due to the blade of the diamond knife during sample preparation. The manual mixing (Figure 5(a)) shows important agglomerations in the order of 10 microns whereas they are diminishing around 3 microns for sonication (Figure 5(b)). Finally, the high shear mixing seems to be a relevant technique for nano-dispersion showing agglomerates smaller than 1 micron (Figure 5(c)). Figure 6 presents the initial storage modulus as function of the size of the agglomerates obtained after the dispersion by manual mixing, (A1), and (B1) techniques. The first method shows a high level of aggregation compared to the (B1) 5 passes blend which probably has a fully exfoliated morphology. As illustrated by the $G^{\prime}$ data, there is an increase in elasticity of more than two decades between (A1) and (B1) blends. This is attributed to an important change in the internal structure of the nanoclay platelets and also confirming the gel-like 3D network structure.

3.2. RTM Shear Simulation and Process Limitations. In order to simulate an RTM injection and relate it to the reorganization of the nanoclays with the resin flow, a rheology cycle was imposed to the most viscous (B1) blend that underwent 10 passes through the HSM system. The choice of this particular blend was based on the fact that it is the one showing the most important morphological changes. The imposed shear cycle combines shear and rest periods as illustrated in Figure 7. This simulation is carried out by varying the shear rate three times. At the initial state (quasistatic), the shear rate is kept constant at $0.1(1 / \mathrm{s})$. The initial shear rate was chosen in order to reproduce the initial static state of the resin before injection. This step is followed by a sudden increase of the shear rate to $1000 \mathrm{~s}^{-1}$ representing the resin injection into the mold cavity taking less than 25 seconds. 


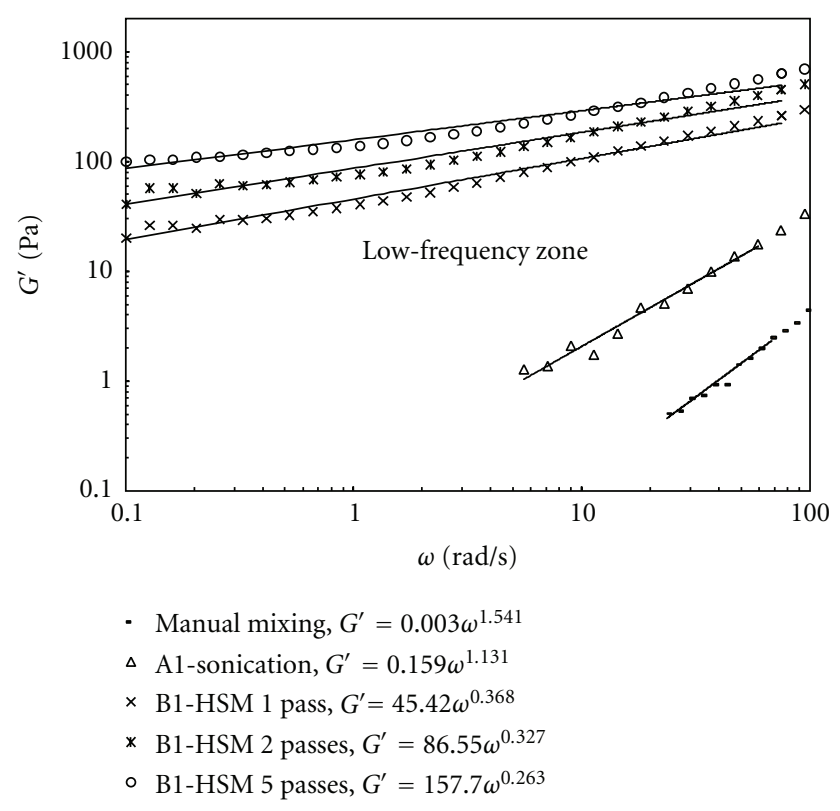

(a)

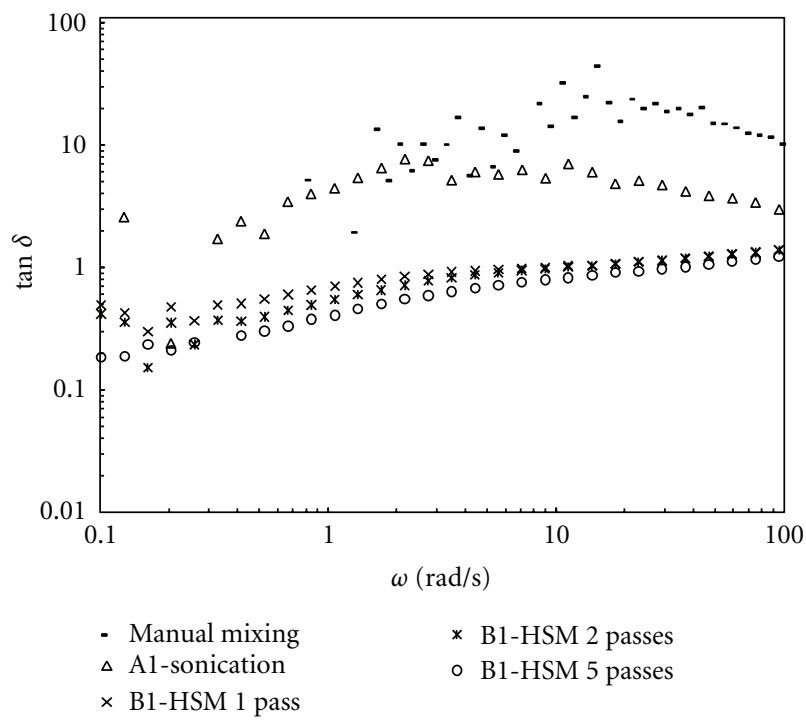

(b)

FIGURE 4: Internal structure behavior of UP resin with 3\% wt C30B nanoclays for various mixing methods (a) storage modulus of (b) $\tan \delta$.

After this period, the resin is maintained on a static state (i.e., $0.1(1 / \mathrm{s}))$ for 25 minutes. During this quasistate period at constant shear rate, the resin viscosity increase from $1.8 \mathrm{~Pa} . \mathrm{s}$ to 200 Pa.s. This increment is assumed to be linked to the nanoclays reorganization, since the shear rate is constant and no chemical reaction takes places (no hardener was added to the resin).

At the very beginning of the cycle, the nanocharged resin is at rest and the initial exfoliated structure of the platelets randomly disorganized. This leads to a very high viscosity of $250 \mathrm{~Pa}$.s on the first two minutes. When the resin is injected at a shear rate of $1000 \mathrm{~s}^{-1}$, the viscosity decreases abruptly

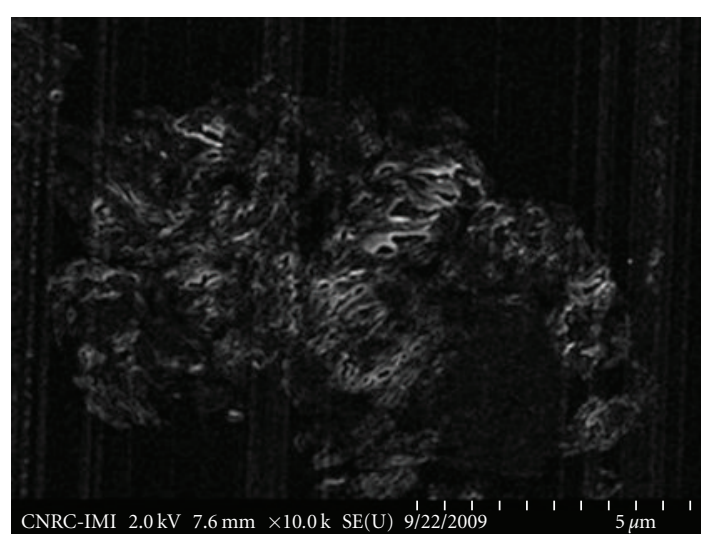

(a)

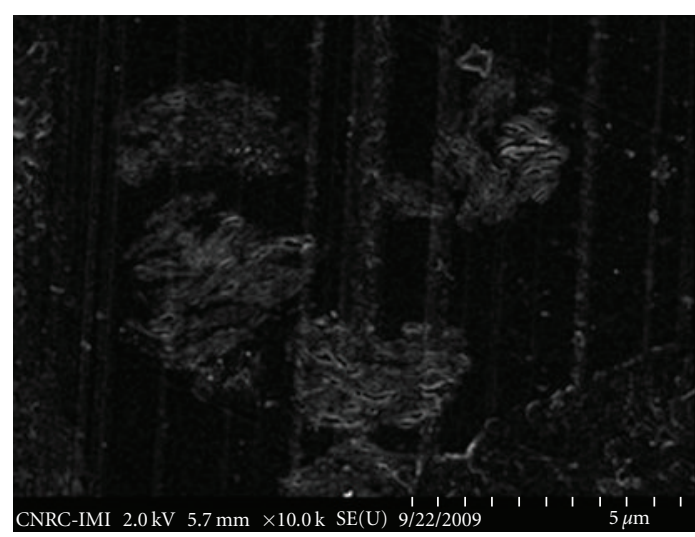

(b)

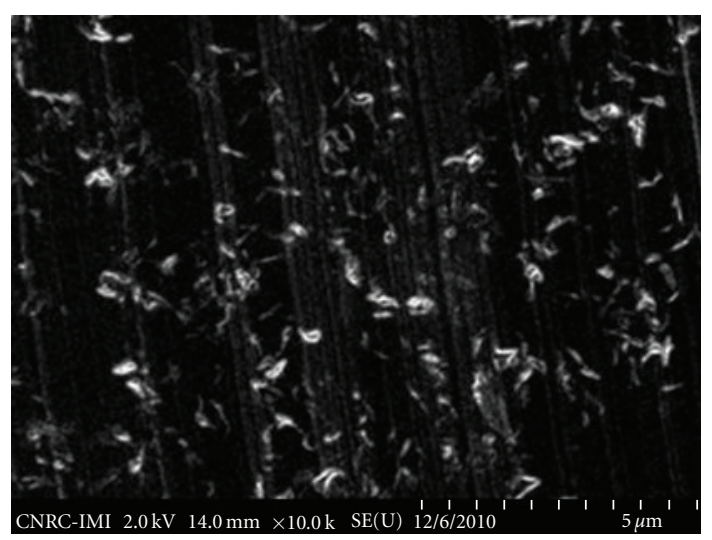

(c)

FIGURE 5: SEM micrograph of nanocharged resin with 3\% wt C30B using different dispersion methods: (a) manual mixing, (b) A1sonication, and (c) B1-HSM.

to $1.8 \mathrm{~Pa} . \mathrm{s}$ and the original nano-structure is destroyed. The particles at this point are oriented in the fluid flow direction. After the filling is completed, at around 3 minutes, the shear is released and the viscosity gradually increases until it reaches its initial value after 10 minutes. There is a restructuration of the nanoparticles in the blend which disorganized themselves to their original exfoliated structure after this period. This rheology simulation gives precious 


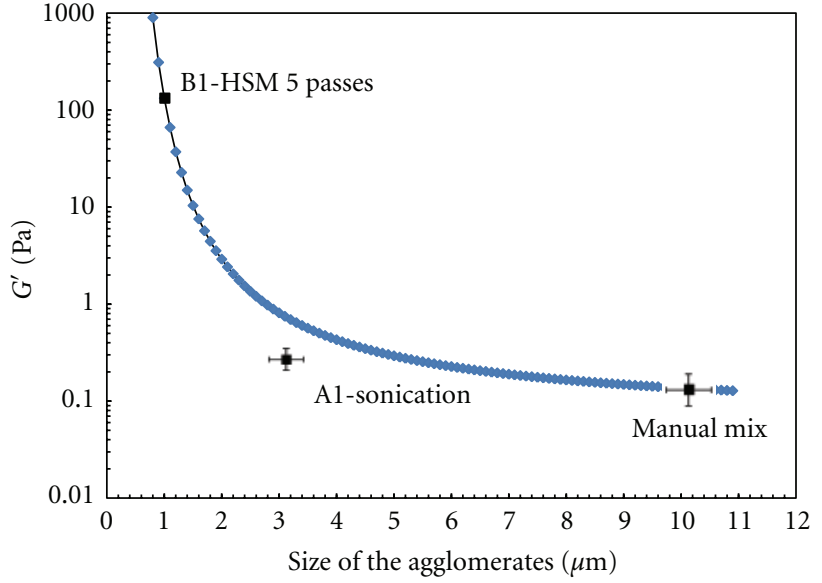

FIGURE 6: Variation of the storage modulus according to the mixing technique.

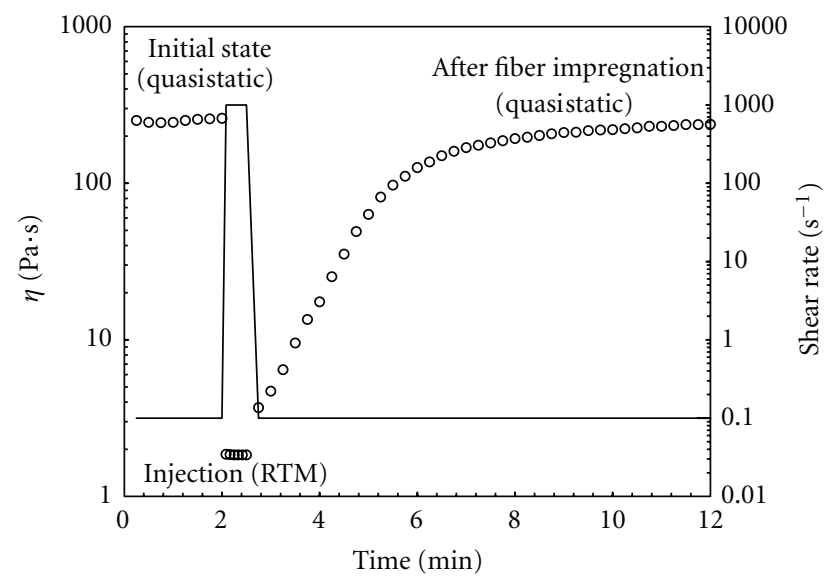

FIGURE 7: RTM injection simulation on the rheometer (B1-HSM 10 passes).

indication about the time necessary for the exfoliated nanoblend to reach a viscosity small enough for injection in addition to its ability to recover rapidly to its original probable exfoliated state which is of interest for the improvement of the properties of the final part.

The gel point is another important feature of the nanocharged mixtures and it is defined as the required time for the covalent bound of the monomer to connect across the network to form the infinite network [15]. At that time, the polymer viscosity tends to infinity. Numerous techniques $[19,34,36]$ can be used to determine the gel point, such as the crossing point between the baseline and the tangent drawn from the turning point of $G^{\prime}$ curve, the cross-over of the modulus $G^{\prime}$ and $G^{\prime \prime}$, or when the $\tan \delta$ becomes invariant with frequency. The chosen criteria will depend on the system being studied as well as the stoichiometry of the different components. One of the techniques selected in this study was successfully used for epoxy prepregs, consisting in determining the gel time at the maximum of the $\tan \delta$ [36]. It was decided for the gel point study to focus only on the low-frequency range in order to be representative of the

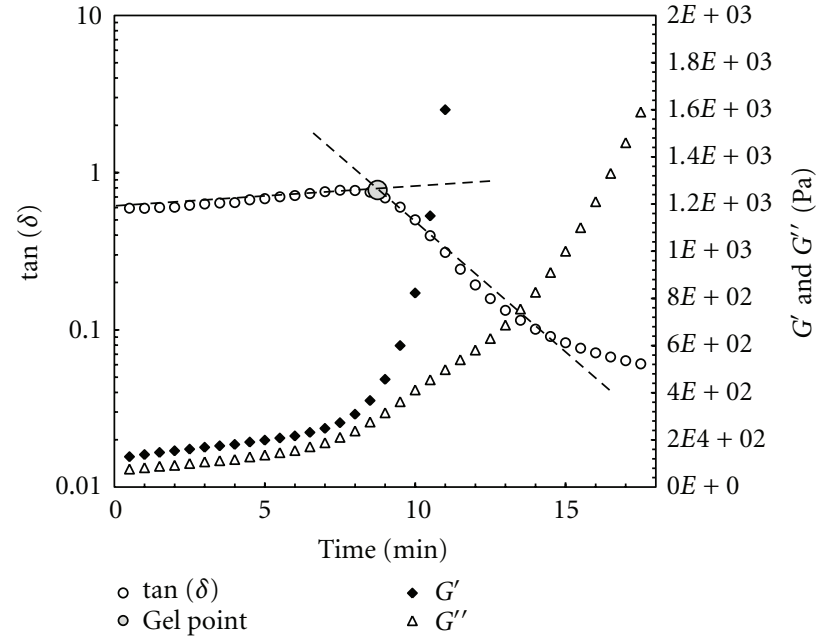

Figure 8: Storage and loss moduli and $\tan \delta$ during the cure of B1HSM 5 passes blend at $23^{\circ} \mathrm{C}$.

actual manufacturing process. To obtain consistent results, the frequency of all experiments was set to $1 \mathrm{~Hz}$ in the linear viscoelastic region. Experiments were then conducted in time sweep mode as shown in Figures 8 and 9.

Figure 8 illustrates the evolution of $G^{\prime}, G^{\prime \prime}$, and $\tan \delta$ during the cure of the B1-HSM 5 passes blend at $23^{\circ} \mathrm{C}$. It can be seen that $G^{\prime}$ is always higher than $G^{\prime \prime}$ because of the gel-like structure of the blend. As a consequence, no crossover is observed between $G^{\prime}$ and $G^{\prime \prime}$. At around 9 minutes from the beginning of cure, there is a sudden increase of the storage modulus to infinity which indicates an important change in the polymer structure. At this point, the $\tan \delta$ curve reaches a maximum close to 1 . This is an indication of the gel formation which denotes the beginning of the cross-linking of the polymer. The calculation of the gel time with this method was carried out on the resin/nanoparticles blends mixed with different techniques as illustrated in Figure 9(a) at the same temperature and frequency. As shown, the blends mixed with a high shear mixer result in the lowest gel times, between 3 and 15 minutes. Moreover, it is observed that the gel time decreases proportionally with the number of passes in the mixer for the HSM technique. As of the hand mixed and sonicated samples, their gel point is slightly inferior to the pure resin due to the supposed catalytic effect of the nanoclays. Since the nanoclays are not well dispersed with this techniques compared to HSM mixtures, the catalytic effect is limited.

The gelification point is often defined as the time at which the $G^{\prime}$ exceeds $G^{\prime \prime}$ (i.e., $\tan \delta=1$ ), but this point corresponds to a high resin viscosity. In LCM process analysis, the processing gel time may be defined as the point at which the resin viscosity curve has a slope of $10 \%$ [26]. This criterion results in a viscosity increase between 2 to 5 times from the initial value. At this point the resin will not flow under normal injection pressures [26]. Figure 9(b) illustrates the evolution of the complex viscosity with time during cure. This processing gel time calculated from complex viscosity is in good agreement with the data obtained from 

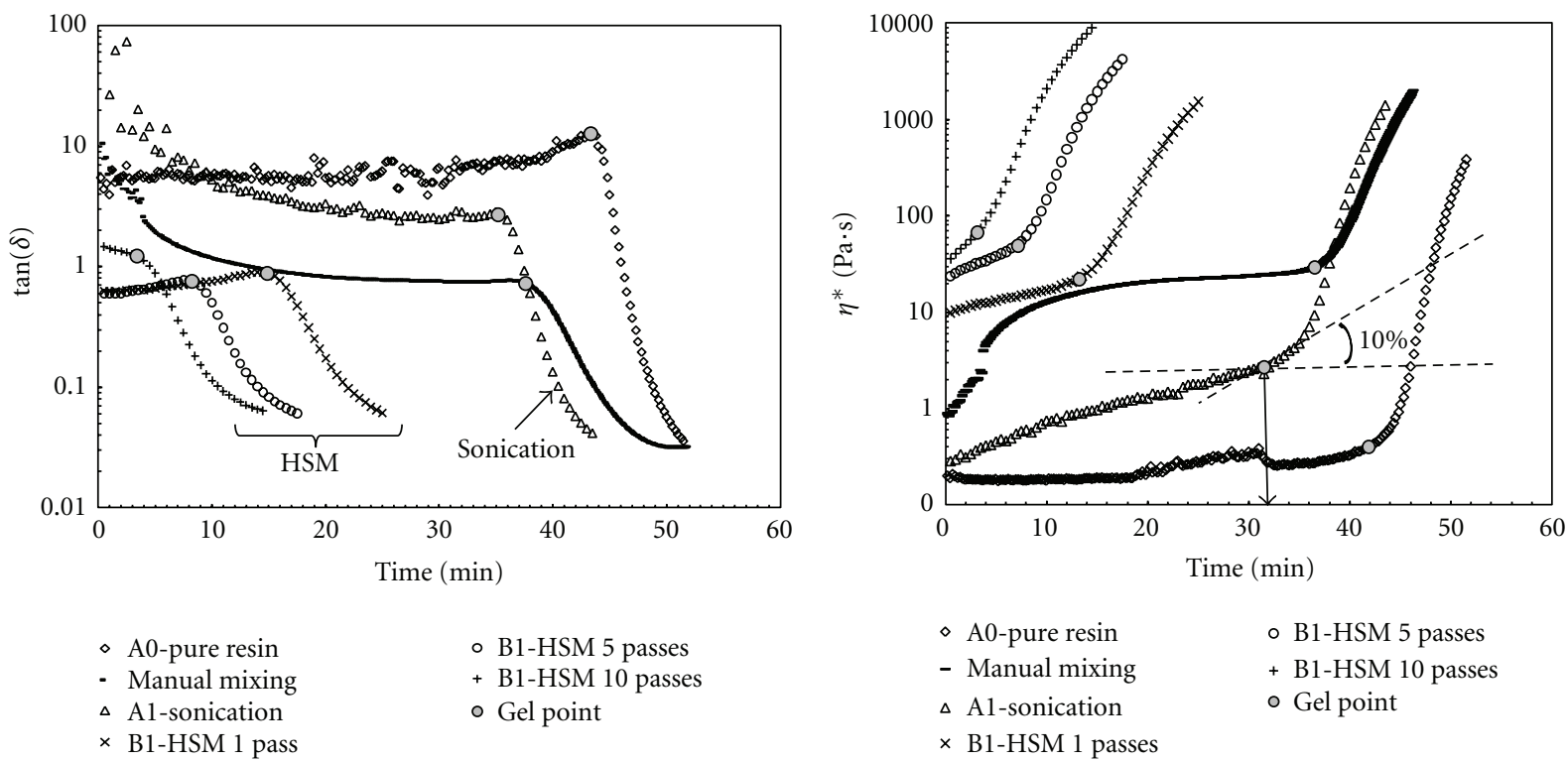

- B1-HSM 5 passes

+ B1-HSM 10 passes

- Gel point

- A0-pure resin

- Manual mixing

$\triangle$ Al-sonication

$\times$ B1-HSM 1 passes

(a)

(b)

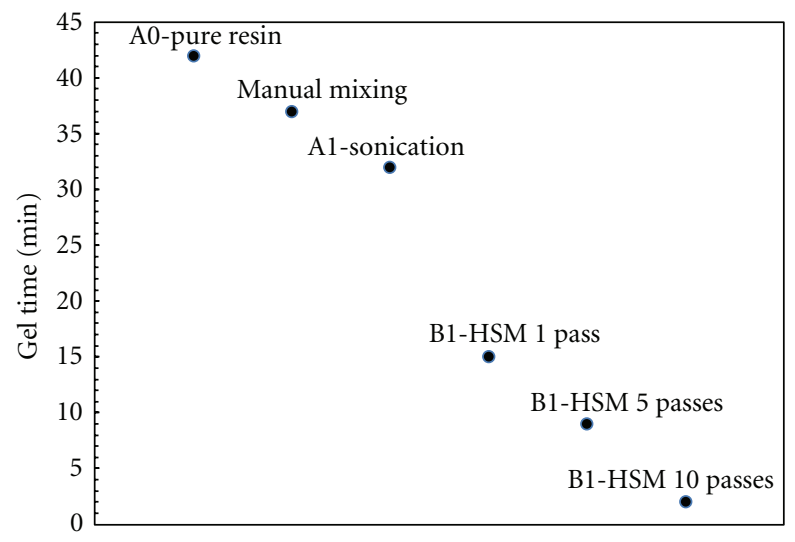

(c)

Figure 9: Gel time at $23^{\circ} \mathrm{C}$ UP resin with $3 \%$ wt of C30B mixed with various dispersion techniques: (a) method of maximum tan $\delta$, (b) $10 \%$ slope of $\eta^{*}$, and (c) gel point tendency obtained with the maximum $\tan \delta$.

the maximum of $\tan \delta$. The catalytic effect of the nanoclay tends to decrease the gel time due to the increased interactions between nanoclay platelets and the polymer resin. Table 2 resumes the gelification time for each system according to the mixing method. Figure 9(c) summarizes the gelification times calculated from the maximum of $\tan \delta$ according to the mixing method. The gelification time has been reduced in 17 minutes between (A1) and (B1) blends. This is mainly due to an enhanced dispersion state and probable exfoliation, which results in a greater surface for interaction between the polymer matrix and the clays. This interfacial region acts as a catalyst and accelerates the curing reaction.

3.3. Catalytic Effect of the Nanoclays. As illustrated by the gel time results, the addition of nanoclays has a nonnegligible impact on the polymerization process. In order to better understand this catalytic effect on the cross-linking reaction of the UP resin, samples of the different blends were isothermally maintained at $70^{\circ} \mathrm{C}$ for various dwell times. The catalyst was then added to the blend and the heat of reaction was analyzed with an M-DSC using a constant heating rate process. The residual heat of reaction was compared to the total heat of reaction generated during the cure of the pure resin. In addition, the samples exposed at $70^{\circ} \mathrm{C}$ were compared to the samples stored at $-18^{\circ} \mathrm{C}$, so-called control samples. Neat resin samples were exposed to the same isothermal condition to take into account the styrene evaporation which has an influence on the released heat of reaction. For that reason, a correction of the total heat is made for all stored samples. The nonreleased heat due the evaporation of styrene for the pure resin sample, $\Delta H_{\text {pure resin, }}$, during storage at $70^{\circ} \mathrm{C}$ was calculated as follows:

$$
\Delta H_{\text {pure resin }}=H_{\text {pure resin at }-18^{\circ} \mathrm{C}}-H_{\text {pure resin at } 70^{\circ} \mathrm{C}} \text {. }
$$

The evaporation of the cross-linking agent (styrene) during storage lowers the total heat or reaction of the resin a quantity 
TABLE 2: Gel time results using two different calculation methods.

\begin{tabular}{|c|c|c|c|c|}
\hline & & & $\begin{array}{c}\text { Maximum } \tan \delta \\
(\min ) \\
\text { Figure } 9(\mathrm{a})\end{array}$ & $\begin{array}{c}\text { 10\% slope } \\
\text { (min) } \\
\text { Figure 9(b) }\end{array}$ \\
\hline \multicolumn{3}{|c|}{ Pure resin } & 44 & 42 \\
\hline \multirow{5}{*}{$\begin{array}{l}\text { 3\% cloisite } \\
\text { 30B }\end{array}$} & \multicolumn{2}{|c|}{ Manual mixing } & 38 & 37 \\
\hline & \multicolumn{2}{|c|}{ A1-sonication } & 36 & 32 \\
\hline & \multirow{3}{*}{$\begin{array}{l}\text { B1 } \\
\text { HSM }\end{array}$} & 1 pass & 15 & 14 \\
\hline & & 5 passes & 9 & 8 \\
\hline & & 10 passes & 3 & 3 \\
\hline
\end{tabular}

TABLE 3: Storage temperature influence on nanocharged resin using HSM and sonication dispersion techniques.

\begin{tabular}{|c|c|c|c|c|c|c|c|}
\hline \multirow{2}{*}{$\begin{array}{l}\text { Isothermal } \\
\text { temperature } \\
\left({ }^{\circ} \mathrm{C}\right)\end{array}$} & \multirow{2}{*}{$\begin{array}{c}\text { Dwell time } \\
\text { (h) }\end{array}$} & \multicolumn{2}{|c|}{ Pure resin } & \multicolumn{2}{|c|}{ Sonication A1 } & \multicolumn{2}{|c|}{ HSM B1-5 passes } \\
\hline & & $H_{\text {res }}(\mathrm{J} / \mathrm{g})$ & $\Delta H_{\text {res }}(\mathrm{J} / \mathrm{g})$ & $H_{\text {res }}(\mathrm{J} / \mathrm{g})$ & $\alpha_{\text {nano }}{ }^{1}(\%)$ & $H_{\text {res }}(\mathrm{J} / \mathrm{g})$ & $\alpha_{\text {nano }}{ }^{1}(\%)$ \\
\hline-18 & 24 & 279.8 & - & 259.7 & 6.5 & 273.1 & 4.4 \\
\hline \multirow{4}{*}{70} & 1 & & & & & 224.6 & 18.4 \\
\hline & 1.5 & & & & & 214.2 & 21.5 \\
\hline & 2 & & & & & 166.7 & 38.5 \\
\hline & 6 & 260.1 & 19.7 & 214.7 & 14.4 & & \\
\hline 70 & 12 & 243.6 & 36.2 & 206.9 & 15.1 & & \\
\hline 70 & 24 & 239.3 & 40.5 & 197.1 & 17.6 & & \\
\hline
\end{tabular}

${ }^{1}$ Calculation based on $H_{\text {res }}$ of the corresponding pure resin storage

equals to $\Delta H_{\text {pure resin. }}$ As shown in Table 3, exposing the pure resin at $70^{\circ} \mathrm{C}$, for long periods, results in a decrement of the heat of reaction of $9.5 \%$ and $14.5 \%$ after 6 and 24 hours, respectively. Therefore, for the nanocomposite samples maintained at $70^{\circ} \mathrm{C}$, the total heat of reaction has to be compared to the one of the pure resin under similar thermal treatment $\left(H_{\text {pure resin at } 70^{\circ} \mathrm{C}}\right)$. Thus, the degree of cure associated to the catalytic effect of the nanoclays $\alpha_{\text {nano }}$ was calculated based on the total heat of reaction generated during cure of the nanocomposites and the one of the pure resin:

$$
\alpha_{\text {nano }}=1-\left(\frac{H_{\text {blend }}}{H_{\text {pure resin }}}\right),
$$

where, $H_{\text {blend }}$ is the heat of reaction of the nanocharged blend and $H_{\text {pure resin }}$ the heat of reaction for the pure resin, both at $70^{\circ} \mathrm{C}$ and at the same dwell time. Figure 10 shows the results of two MDSC tests of the sonicated blend (A1) maintained at $-18^{\circ} \mathrm{C}$ and $70^{\circ} \mathrm{C}$ during 24 hours. It can be seen that the residual heat of reaction after thermal exposure has decreased by $10 \%$ at $-18^{\circ} \mathrm{C}$ and by $17.6 \%$ at $70^{\circ} \mathrm{C}$. This clearly indicates the influence of the nanoclays on the cure reaction of the unsaturated polyester resin. Table 3 presents the resulting degree of cure $\alpha_{\text {nano }}$ after exposing the nanocomposites at these temperatures.

As for the HSM blend (B1), this catalytic effect of nanoclays is very important. The degree of cure $\alpha_{\text {nano }}$ reaches $18 \%$ after $1 \mathrm{~h}$ of exposition and $38.5 \%$ after $2 \mathrm{~h}$ at $70^{\circ} \mathrm{C}$. After this point, the resin gels and it is no longer possible

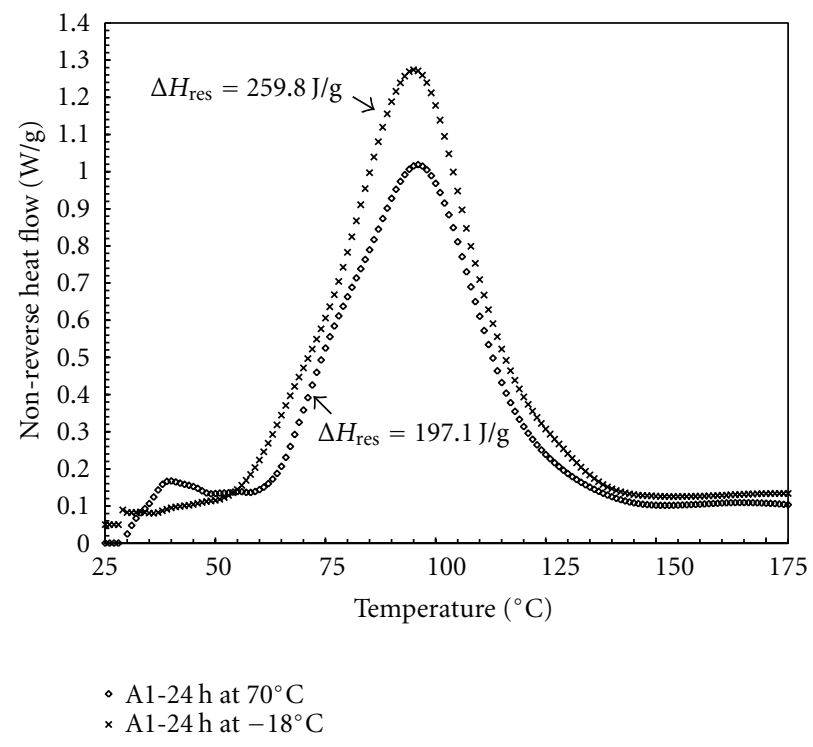

Figure 10: Heat of reaction of the sonicated 3\%wt C30B nanocharged resin exposed at $70^{\circ} \mathrm{C}$ and maintained at $-18^{\circ} \mathrm{C}$ in freezer (control) for $24 \mathrm{~h}$. Catalyst added to the mix just before $\mathrm{M}$ DSC analysis.

to be add the catalyst. The differences in cure reaction between the (A1) and (B1) blends can be attributed to an increased dispersion and possible exfoliation of the HSM blend. This catalytic effect of nanoclay platelets is probably 


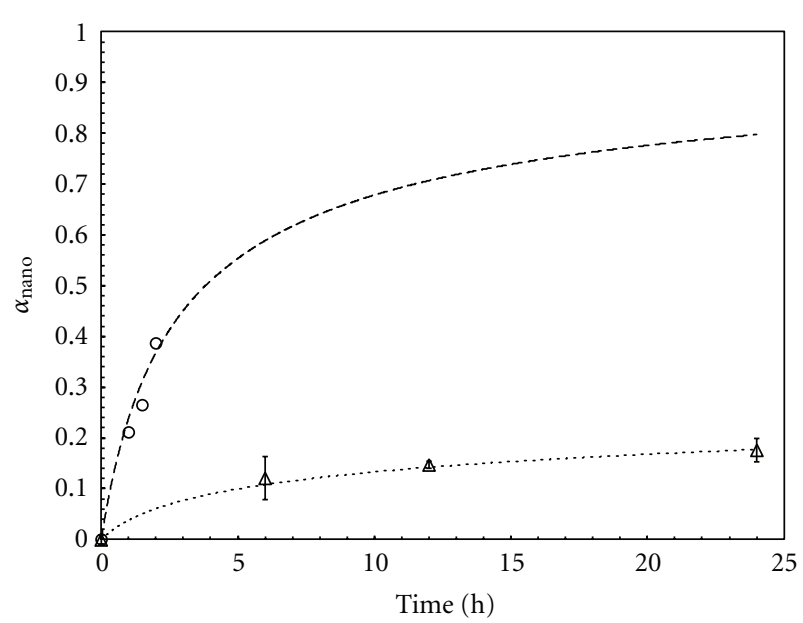

- Experimental data: HSM $\Delta$ Experimental data: sonication --- Model: HSM …... Model: sonication

FIGURE 11: Modelling of conversion-time curves for sonicated and HSM blends. Experimental data comes from M-DSC analyses. Fitting curves are polynomial.

due to the existence of attractive forces between the clay and the polymer matrix. The cation-exchange capacity of the nanoclay influences the cure reaction. This acceleration is induced by the alkylammonium ions contained in the surface treatment of the nanocharges [20].

Figure 11 shows the results of the measured degree of cure $\alpha_{\text {nano }}$ for (A1) and (B1) blends as a function of exposition time at $70^{\circ} \mathrm{C}$. A phenomenological autocatalytic model was used to model the cure reaction of both blends. The degree of cure was evaluated by an $n$ th-order model as follows $[26,34]$ :

$$
\frac{d \alpha}{d t}=K_{\mathrm{A}} \cdot(1-\alpha)^{n},
$$

where $\alpha$ is the degree of polymerization, $n$ the reaction order, and $K_{A}$ the rate constant given by an Arrhenius temperature dependence defined as

$$
K_{\mathrm{A}}=K_{0} \exp \left(\frac{-E_{A}}{R \cdot T}\right),
$$

where $K_{0}$ is the Arrhenius constant, $E_{\mathrm{A}}$ is the activation energy, and $R$ is the ideal gas constant. Equations (10) and (11) are widely used to model the cure of many polymer systems such as polyester and epoxies. This model is used on the assumption that only one kind of reaction may represent the whole cure process [34]. The parameters of the proposed cure kinetics model were obtained by fitting the experimental data extracted from M-DSC tests and presented in Table 3. The coefficients of the two models are shown in Table 4. As illustrated in Figure 11, there is a good agreement between the M-DSC experiments and the proposed models. This indicates that an autocatalytic reaction of the polymer can be started due to the presence of nanoclay particles. Moreover, these results demonstrate that the degree of exfoliation accelerates the autocatalytic cure
TABLE 4: $K$ and $m$ constants of the autocatalytic model for UP resin/nanoclay systems depending on the dispersion method.

\begin{tabular}{lcc}
\hline$T=70^{\circ} \mathrm{C}$ & Sonication model & HSM model \\
\hline$K_{A}(1 / \mathrm{min})$ & 0.000875 & 0.00575 \\
$n$ & 16.5 & 2.7 \\
\hline
\end{tabular}

reaction. It is then concluded that the exfoliation of MMT changes the cure rate of the UP resin tested on this work. Similar results were reported in the past for epoxy resins [37]. This could also indicate that the interfacial region between the clay and the polymer may dominate the properties of the blend.

\section{Conclusion}

The scope of this work was to study the nanoclays dispersion in an UP resin and by means of three different mixing techniques. Rheology tests based on shear and SAOS experiments revealed the differences between the manual mixing, sonication, and high shear mixing techniques. Notably, the shear thinning behavior is a result of the morphological change of the blend due to the rearrangement of the silicate nanoclays. Furthermore the intercalated and exfoliated structure has shown a gel-like structure of high shear mixed blends. This is, however, a weak gel since $\tan \delta$ is in the order of $10^{-1}$. This gel-like structure is a direct consequence of the interaction between the polymer and the nano-platelets leading to the creation of a 3D network in the liquid.

The high shear mixing has the highest elastic modulus (100 Pa) and initial viscosity (up to 250 Pa.s compared to other mixing techniques). However, the viscosity decreases at high shear rate due to the reorientation of the nanoclays. The viscosity reaches $2 \mathrm{~Pa}$.s at high shear which makes it possible to process the blend by RTM. The dispersion was also verified by SEM microscopy showing agglomerates of 10 microns for the manual mixing and less than 1 micron for the high shear technique. The nanoclays seem also to have a catalyst effect on the resin system, showing a reduction of the gel time due to their exfoliation state. The neat resin showed a gel time of 45 minutes whereas the 10 passes HSM blend jellified at around 3 minutes. This phenomenon has to be taken into account for proper composites molding. The DSC study confirms the catalytic effect of the nanoclays showing a degree of cure of $38.5 \%$ for the high shear mix after 2 hours of exposition at a $70^{\circ} \mathrm{C}$.

This study illustrates how well-dispersed nanoclays in UP resin bring many interesting structural changes in the polymer matrix. This work also shows that processing may be achievable since the time to orient the nanoparticles in the direction of fluid flow is within seconds and the restructuration to their initial random disorganized structure takes few minutes. Future work will focus on the use of HSM technique for manufacturing biocomposite parts improved by nanoclay reinforcing of the bioresin. 


\section{Abbreviations}

$\begin{array}{ll}\text { FEG: } & \begin{array}{l}\text { Field emission gun (scanning electron } \\ \text { microscope) }\end{array} \\ G^{\prime}: & \text { Elastic modulus } \\ G^{\prime \prime}: & \text { Loss modulus } \\ \text { HSM: } & \text { High shear mixing } \\ \text { LCM: } & \text { Liquid composite molding } \\ \text { LVE: } & \text { Linear viscoelastic } \\ \text { M-DSC: } & \text { Modulated differential scanning calorimetry } \\ \text { MMT: } & \text { Montmorillonite } \\ \text { phr: } & \text { Parts per hundred } \\ \text { RTM: } & \text { Resin transfer molding } \\ \text { SCRIMP: } & \text { Seeman composite resin infusion molding } \\ & \text { process } \\ \text { SEM: } & \text { Scanning electron microscopy } \\ \text { TEM: } & \text { Transmission electronic microscopy } \\ \text { UP: } & \text { Unsaturated polyester resin } \\ \text { VARI: } & \text { Vacuum assisted resin infusion } \\ \text { \% wt: } & \text { Weight percentage } \\ \text { XRD: } & \text { X-Ray diffraction } \\ \omega: & \text { Frequency (rad/s) } \\ \text { tan } \delta: & \text { Damping factor. }\end{array}$

\section{Acknowledgments}

The authors acknowledge the support provided by the Chair of High Performance Composite (CCHP) and the Center for Applied Research on Polymers and Composites (CREPEC). The financial contribution of the Natural Sciences and Engineering Research Council of Canada (NSERC) is also greatly appreciated.

\section{References}

[1] I. Ortega, Fabrication et caracterisation de nanocomposites a matrice epoxy, M.S. dissertation, Ecole Polytechnique, Montreal, Canada, 2008.

[2] S. Abend and G. Lagaly, "Sol-gel transitions of sodium montmorillonite dispersions," Applied Clay Science, vol. 16, no. 3-4, pp. 201-227, 2000.

[3] S. S. Ray and M. Okamoto, "Polymer/layered silicate nanocomposites: a review from preparation to processing," Progress in Polymer Science, vol. 28, no. 11, pp. 1539-1641, 2003.

[4] Y. Rao and T. N. Blanton, "Polymer nanocomposites with a low thermal expansion coefficient," Macromolecules, vol. 41, no. 3, pp. 935-941, 2008.

[5] D. Dean, A. M. Obore, S. Richmond, and E. Nyairo, "Multiscale fiber-reinforced nanocomposites: synthesis, processing and properties," Composites Science and Technology, vol. 66, no. 13, pp. 2135-2142, 2006.

[6] S. S. Ray, "Rheology of polymer/layered silicate nanocomposites," Journal of Industrial and Engineering Chemistry, vol. 12, no. 6, pp. 811-842, 2006.

[7] S. Zainuddin, M. V. Hosur, Y. Zhou, A. Kumar, and S. Jeelani, "Durability study of neat/nanophased GFRP composites subjected to different environmental conditioning," Materials Science and Engineering A, vol. 527, no. 13-14, pp. 3091-3099, 2010.

[8] A. Lele, M. Mackley, G. Galgali, and C. Ramesh, "In situ rheo$\mathrm{x}$-ray investigation of flow-induced orientation in layered silicate-syndiotactic polypropylene nanocomposite melt," Journal of Rheology, vol. 46, no. 5, pp. 1091-1110, 2002.

[9] C.-K. Lam, K.-T. Lau, H.-Y. Cheung, and H.-Y. Ling, "Effect of ultrasound sonication in nanoclay clusters of nanoclay/epoxy composites," Materials Letters, vol. 59, no. 11, pp. 1369-1372, 2005.

[10] S. Lakshminarayanan, B. Lin, G. A. Gelves, and U. Sundararaj, "Effect of clay surfactant type and clay content on the eheology and morphology of uncured Fluoroelastomer/clay nanocomposites prepared by melt-mixing," Journal of Applied Polymer Science, vol. 112, no. 6, pp. 3597-3604, 2009.

[11] Y. Zhong and S.-Q. Wang, "Exfoliation and yield behavior in nanodispersions of organically modified montmorillonite clay," Journal of Rheology, vol. 47, no. 2, pp. 483-495, 2003.

[12] I. Ortega, C. Billotte, and E. Ruiz, "Thermo-mechanical and rheologicalcharacterization of various epoxy-based nanocomposites for high performance composites," in Proceedings of the 4th International Symposium on Polymer Nanocomposites Science and Technology, Quebec, Canada, 2007.

[13] J. Ren, B. F. Casanueva, C. A. Mitchell, and R. Krishnamoorti, "Disorientation kinetics of aligned polymer layered silicate nanocomposites," Macromolecules, vol. 36, no. 11, pp. 41884194, 2003.

[14] R. Krishnamoorti, J. Ren, and A. S. Silva, "Shear response of layered silicate nanocomposites," Journal of Chemical Physics, vol. 114, no. 11, pp. 4968-4973, 2001.

[15] C. Mobuchon, P. J. Carreau, and M.-C. Heuzey, "Structural analysis of non-aqueous layered silicate suspensions subjected to shear flow," Journal of Rheology, vol. 53, no. 5, pp. 10251048, 2009.

[16] R. Prasad, V. Pasanovic-Zujo, R. K. Gupta, F. Cser, and S. N. Bhattacharya, "Morphology of EVA based nanocomposites under shear and extensional flow," Polymer Engineering \& Science, vol. 44, no. 7, pp. 1220-1230, 2004.

[17] J. Ren, A. S. Silva, and R. Krishnamoorti, "Linear viscoelasticity of disordered polystyrene-polyisoprene block copolymer based layered-silicate nanocomposites," Macromolecules, vol. 33, no. 10, pp. 3739-3746, 2000.

[18] R. Krishnamoorti and K. Yurekli, "Rheology of polymer layered silicate nanocomposites," Current Opinion in Colloid and Interface Science, vol. 6, no. 5-6, pp. 464-470, 2001.

[19] E. Ruiz and C. Billotte, "Predicting the cure of thermosetting polymers: the isoconversion map," Polymer Composites, vol. 30, no. 10, pp. 1450-1457, 2009.

[20] O. Becker, Y.-B. Cheng, R. J. Varley, and G. P. Simon, "Layered silicate nanocomposites based on various highfunctionality epoxy resins: the influence of cure temperature on morphology, mechanical properties, and free volume," Macromolecules, vol. 36, no. 5, pp. 1616-1625, 2003.

[21] B. Gholizadeh, A. Arefazar, and J. Barzin, "Polycarbonate/polyamide 6/nanoclay ternary nanocomposite membranes: preparation, characterisation, and gas separation properties," Polymers and Polymer Composites, vol. 17, no. 3, pp. 181-187, 2009.

[22] D. H. Yu, B. Wang, Y. Feng, and Z. P. Fang, "Investigation of free volume, interfacial, and toughening behavior for cyanate ester/bentonite nanocomposites by positron annihilation," Journal of Applied Polymer Science, vol. 102, no. 2, pp. 15091515, 2006.

[23] G. Choudalakis, A. D. Gotsis, H. Schut, and S. J. Picken, "The free volume in acrylic resin/laponite nanocomposite coatings," European Polymer Journal, vol. 47, no. 3, pp. 264-272, 2011.

[24] F. Roman, S. Montserrat, and J. M. Hutchinson, "On the effect of montmorillonite in the curing reaction of epoxy 
nanocomposites," Journal of Thermal Analysis and Calorimetry, vol. 87, no. 1, pp. 113-118, 2007.

[25] E. Ruiz and F. Trochu, "Multi-criteria thermal optimization in liquid composite molding to reduce processing stresses and cycle time," Composites Part A:, vol. 37, no. 6, pp. 913-924, 2006.

[26] E. Ruiz, F. Waffo, J. Owens, C. Billotte, and F. Trochu, "Modeling of resin cure kinetics for molding cycle optimization," in Proceedings of the International Conference in Flow Processes in Composite Materials (FPCM '06), Ecole des Mines de Douai, Douai, France, 2006.

[27] W. K. Goertzen, X. Sheng, M. Akinc, and M. R. Kessler, "Rheology and curing kinetics of fumed silica/cyanate ester nanocomposites," Polymer Engineering \& Science, vol. 48, no. 5, pp. 875-883, 2008.

[28] K. C. Cole, J. J. Hechler, and D. Noel, "A new approach to modeling the cure kinetics of epoxy amine thermosetting resins. 2. Application to a typical system based on bis[4(diglycidylamino)phenyl]methane and bis(4-aminophenyl) sulfone," Macromolecules, vol. 24, no. 11, pp. 3098-3110, 1991.

[29] T. Lan, P. D. Kaviratna, and T. J. Pinnavaia, "Epoxy selfpolymerization in smectite clays," Journal of Physics and Chemistry of Solids, vol. 57, no. 6-8, pp. 1005-1010, 1996.

[30] L. Botta, R. Scaffaro, F. P. L. A. Mantia, and N. T. Dintcheva, "Effect of different matrices and nanofillers on the rheological behavior of polymer-clay nanocomposites," Journal of Polymer Science, Part B, vol. 48, no. 3, pp. 344-355, 2010.

[31] F. Bensadoun, N. Kchit, C. Billotte, S. Bickerton, F. Trochu, and E. Ruiz, "A study of nanoclay reinforcement of biocomposites made by liquid composite molding," International Journal of Polymer Science, vol. 2011, Article ID 964193, 10 pages, 2011.

[32] C. H. Dan, M. H. Lee, Y. D. Kim, B. H. Min, and J. H. Kim, "Effect of clay modifiers on the morphology and physical properties of thermoplastic polyurethane/clay nanocomposites," Polymer, vol. 47, no. 19, pp. 6718-6730, 2006.

[33] F. A. Morrison, Understanding Rheology, Oxford University Press, New York, NY, USA, 2001.

[34] E. Ruiz and F. Trochu, "Thermomechanical properties during cure of glass-polyester RTM composites: elastic and viscoelastic modeling," Journal of Composite Materials, vol. 39, no. 10, pp. 881-916, 2005.

[35] M. Hamdine, M.-C. Heuzey, and A. Bégin, "Effect of organic and inorganic acids on concentrated chitosan solutions and gels," International Journal of Biological Macromolecules, vol. 37, no. 3, pp. 134-142, 2005.

[36] M. Hayaty, M. H. Beheshty, and M. Esfandeh, "A new approach for determination of gel time of a glass/epoxy prepreg," Journal of Applied Polymer Science, vol. 120, no. 3, pp. 1483-1489, 2011.

[37] W.-B. Xu, S.-P. Bao, S.-J. Shen, G.-P. Hang, and P.-S. He, "Curing kinetics of epoxy resin-imidazole-organic montmorillonite nanocomposites determined by differential scanning calorimetry," Journal of Applied Polymer Science, vol. 88, no. 13, pp. 2932-2941, 2003. 

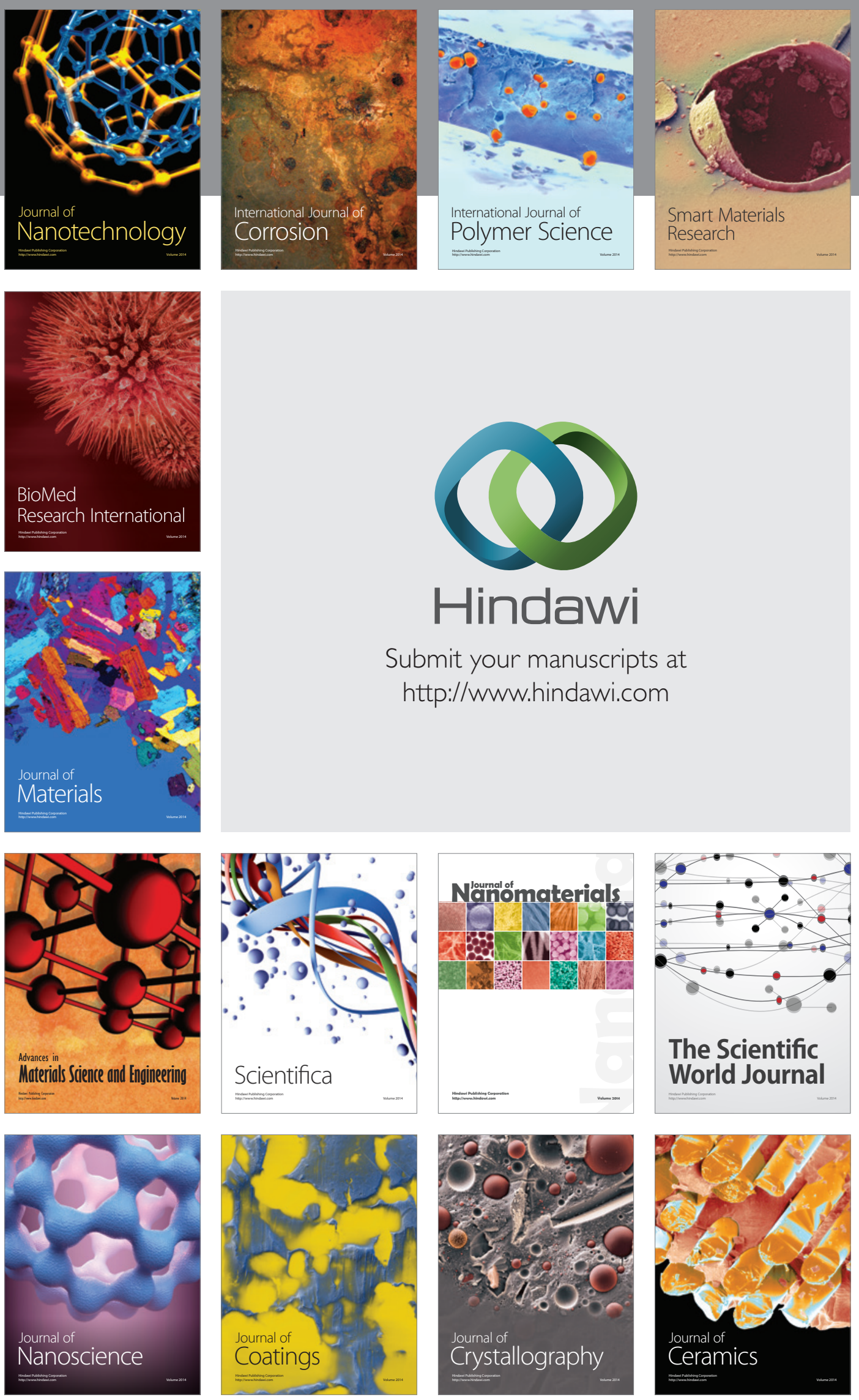

The Scientific World Journal

Submit your manuscripts at

http://www.hindawi.com

\section{World Journal}

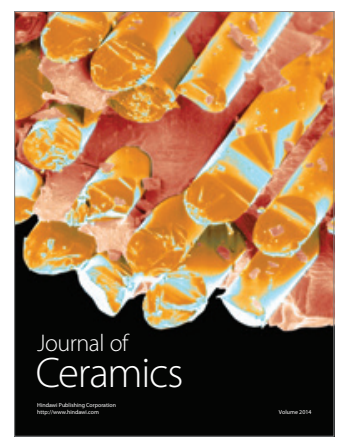

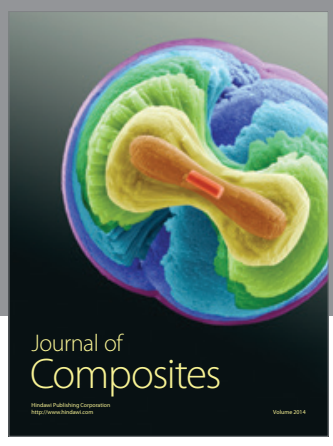
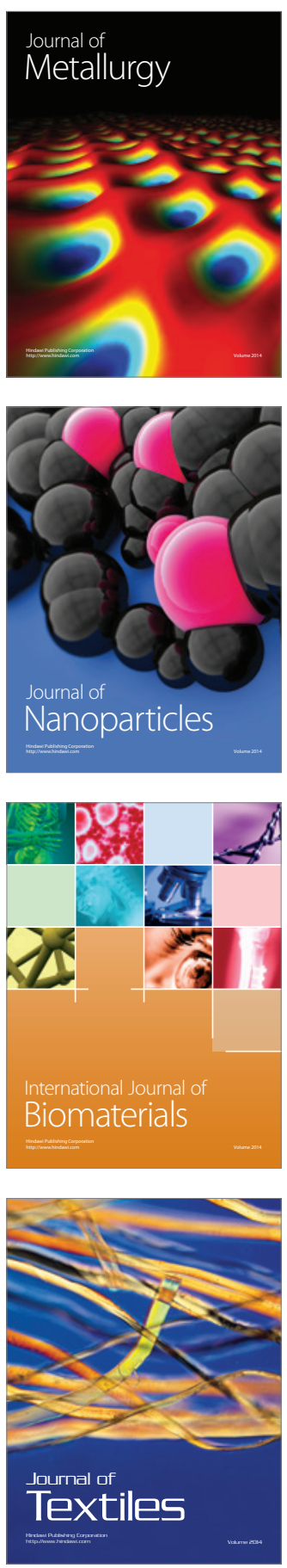